\title{
Fœtale Death in Utero: Maternal Epidemiological and Prognostic Aspects at Sylvanus Olympio Teaching Hospital in Lomé
}

\author{
Baguilane Douaguibe ${ }^{*}$, A. S. Aboubakari², A. Bassowa ${ }^{3}$, D. Ajavon ${ }^{2}$, T. Ketevi ${ }^{3}$, \\ K. E. Logbo-Akey², B. Baramna ${ }^{3}$, K. Fiagnon ${ }^{3}$, K. Akpadza ${ }^{3}$ \\ ${ }^{1}$ Gynecology and Obstetrical Service, CHU Campus, Lomé, Togo \\ ${ }^{2}$ Gynecology and Obstetrical Service CHU, Kara, Togo \\ ${ }^{3}$ Gynecology and Obstetrical Service CHU-SO, Lomé, Togo \\ Email: ^douaguibe@hotmail.com, akilabassowa@gmail.com, ketevitina@yahoo.fr, fbararmnabagou@gmail.com, \\ fiakoj@hotmail.com, akapdza@yahoo.fr, anourislam@yahoo.fr, ddajavon@yahoo.fr
}

\begin{abstract}
How to cite this paper: Douaguibe, B., Aboubakari, A.S., Bassowa. A., Ajavon. D., Ketevi, T., Logbo-Akey, K.E., Baramna, B., Fiagnon, K. and Akpadza, K. (2019) Fœtale Death in Utero: Maternal Epidemiological and Prognostic Aspects at Sylvanus Olympio Teaching Hospital in Lomé. Open Journal of Obstetrics and Gynecology, 9, 511-520.
\end{abstract}

https://doi.org/10.4236/ojog.2019.94050

Received: February 28, 2019

Accepted: April 15, 2019

Published: April 18, 2019

Copyright $\odot 2019$ by author(s) and Scientific Research Publishing Inc. This work is licensed under the Creative Commons Attribution International License (CC BY 4.0).

http://creativecommons.org/licenses/by/4.0/

(c) (i) Open Access

\begin{abstract}
The fetal death In Uterus is relatively a common problem in developing countries. In Africa, the rate of deaths varies from one hospital to another. We wanted to evaluate the prevalence, to describe the epidemiological aspects, etiologies and maternal prognosis associated with fetal deaths in Uterus in 2017 at Sylvanus Olympio Teaching Hospital in Lomé. Patients and methods: This was a retrospective descriptive study conducted from January 1st to December 31st, 2017. We have included all pregnant cases received and treated on the spot for in uterus deaths as defined by the World Health Organization. Medical termination of pregnancy records, intrapartum deaths, less than 22 amenorrhea weeks' pregnancies and complications of abortion were not included. Results: The fetal death rate in uterus was $3.64 \%$. The multigravida and multiparous were respectively $49 \%$ and $41 \%$; the referees were $51 \%, 28 \%$ evacuated; $21 \%$ came on their own. The gestational age of 28 37 weeks was $39 \%$ and $17 \%$ had no prenatal consultation. The analysis has revealed that high blood pressure, preeclampsia, and retroplacental hematomas were the main etiologies associated with fetal deaths in uterus. Conclusion: In uterus fetal deaths remain common in our country. The main causes were hypertension disorders of pregnancy. There were also some unknown causes which could be related to economic or cultural reasons. For instance, autopsies of in uterus deaths and placental anatomopathology examination are not performed because of culture.
\end{abstract}

\section{Keywords}

Fetal Death in Uterus, Etiology, Maternal Prognosis 


\section{Introduction}

The joy of a pregnancy and the expectation of a birth in a family can be turned into a nightmare, depression or sadness for the pregnant woman and the family because of fetal death in uterus. For caregivers, this creates a feeling of decency and guilt.

In uterus fetal death is the fetal death occurring after 22 weeks of pregnancy or $500 \mathrm{~g}$ birth weight if the term is unknown or corrected. The global prevalence of fetal death in uterus from 28 Weeks or fetal weight greater than $1000 \mathrm{~g}$ is estimated to be around $2 \%$, with the average around 5 per 1000 births in high-income countries [1].

The percentage of fetal death in uterus is very low in high-income countries [1]. It is relatively a common problem in developing countries because of insufficient health coverage and low socio-economic status of the population. In Africa, the deaths rate varies from area to area and from country to country. Studies from Amrouche Souhila in Algeria, Kyembwa Mulyumba Michel in Goma (Democratic Republic of Congo) and Andriamandimbison Z in Madagascar found respectively $0.95 \% ; 4.5 \%$ and 5.22\% [2] [3] [4]. In Mali, from 1975 to 2014, the rate of fetal deaths in utero has dropped from $3 \%$ to $1.19 \%$ [5].

In Togo, since the study of Baeta S. in 1991 [6] on the still-birth (1.95\% of fetal death in uterus), few studies have been conducted on this matter at the Hospital Sylvanus Olympio. This motivated us to initiate this work with a general purpose of assessing the prevalence of fetal death in utero in 2017 at the maternity ward inside the hospital of Sylvanus Olympio which is a reference health center in Togo. Specifically, this study will focus on describing the:

- epidemiological aspects of the fetal death In uterus.

- associated etiologies or risk factors for fetal death in uterus.

- maternal prognosis after a fetal death in uterus.

\section{Method and Patients}

\subsection{Type of Study}

This was a retrospective descriptive study conducted from January 1st to December 31st, 2017 in the gynecology and obstetrics' department at the Sylvanus Olympio Teaching Hospital in Lomé.

\subsection{Patients}

All pregnant women received and treated for fetal death in uterus during the study period. We collected our data from the birth and admission records, the hospitalization records of the deliveries on a pre-established survey sheet.

Selection criteria

Inclusion criteria

We included in this study all spontaneous in uterus deaths as defined by the

World Health Organization (WHO). That is, all records of pregnant women having a gestational age of 22 weeks of amenorrhea from the date of last men- 
strual period with absent heart activity at admission or the fetal weight at expulsion were greater than or equal to 500 grams.

Criteria for non-inclusion

We did not include in our study:

$\checkmark$ All pregnant women whose records indicated a pregnancy of less than 22 weeks of amenorrhea or whose fetus weighed less than 500 grams.

$\checkmark$ Records of intrapartum deaths, and deaths at birth.

$\checkmark$ Incomplete files.

$\checkmark$ Records of medical termination of pregnancy regardless of their term.

$\checkmark$ Records of pregnant women discharged for complication of an abortion.

\subsection{Study Variables}

The variables studied here were classified into four groups:

- Epidemiological: Age, gestational age, and mode of admission.

- Obstetrical history: Pregnancy, parity and history of fetal death in uterus.

- Causes or risk factors associated with fetal death in uterus (malaria, pre-eclampsia, anemia, gestational diabetes, eclampsia, placenta Previa, pre-labor rupture of membranes and retroplacental hematomas.

- Maternal prognosis.

\subsection{Analysis and Treatment}

The data were entered into the computer using Word 2013, analyzed and processed using Excel version 2013. The results will be illustrated by tables and pictures.

\section{Results}

\subsection{Epidemiological Data}

$\checkmark$ Frequency of Fetal Deaths in Uterus

Of the 8228 deliveries performed at the maternity of the Teaching Hospital Sylvanus Olympio in Lomé, from January 1st to December 31st, 2017, we recorded 300 cases of fetal death in uterus, a frequency of $3.64 \%$.

$\checkmark$ The Age

The highest age group represented was 20 - 35, or $77.67 \%$, and the average age was 28 year with extremes of 16 and 46 years (Table 1 ).

Mode of Admission

$51 \%$ of pregnant women were referred; $28 \%$ evacuated from different health centers; $21 \%$ came on their own.

Table 1. Distribution of pregnant women by age.

\begin{tabular}{ccc}
\hline & Number of cases & Percentage (\%) \\
\hline$<20$ & 26 & 8.67 \\
{$[20-35]$} & 233 & 77.67 \\
{$[35$ and more $]$} & 41 & 13.66 \\
Total & 300 & 100.00
\end{tabular}




\subsection{Obstetric History}

Gravidity (Table 2)

Parity

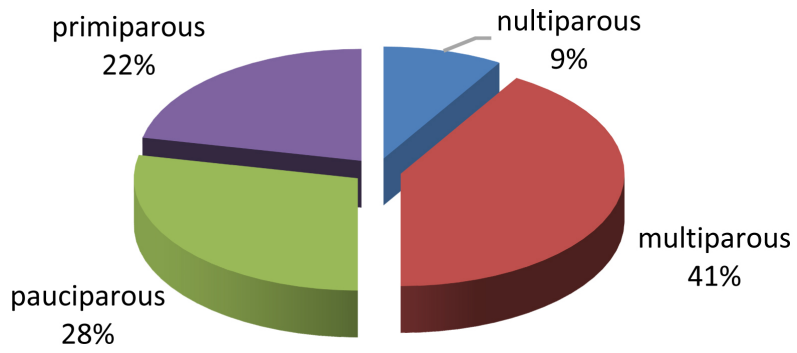

History of Fetal Death in Uterus

$9 \%$ had a history of fetal death in uterus.

Prenatal Consultations

$17 \%$ had not done prenatal consultations; 49\% had done between 1 and 3 prenatal consultations; and $34 \%$ had more than 4 prenatal consultations.

Age of Pregnancy

Table 3 shows the distribution of pregnant women by gestational age.

Delivery Mode

$97.67 \%$ of pregnant women gave birth naturally and $3.33 \%$ delivered by caesarean section.

\subsection{Etiologies or Risk Factors Associated with Pregnancy}

Table 4 shows the distribution of pregnant women according to risk factors or associated etiologies.

Table 2. Distribution of pregnancy by gravidity.

\begin{tabular}{ccc}
\hline & Number & Frequency (\%) \\
\hline Primigravida & 81 & 27 \\
Paucigravida & 71 & 24 \\
Multigravida & 148 & 49 \\
Total & 300 & 100 \\
\hline
\end{tabular}

Table 3. Distribution of pregnant women according to gestational age (Week of Amenorrhea: WA).

\begin{tabular}{ccc}
\hline & Numbers & Frequency (\%) \\
\hline$[22-28]$ & 76 & 25.33 \\
{$[28-37]$} & 117 & 39.00 \\
{$[37-41]$} & 75 & 25.00 \\
{$[41-42]$} & 32 & 10.67 \\
Total & 300 & 100 \\
\hline
\end{tabular}


Table 4. Distribution of pregnant women according to fetal death in utero etiologies.

\begin{tabular}{ccc}
\hline & Number & Frequency (\%) \\
\hline Eclampsia & 04 & 1.33 \\
Severe pre-eclampsia & 85 & 24.00 \\
Fetal malformations & 02 & 0.67 \\
RPH & 40 & 13.33 \\
Placenta previa & 01 & 0.33 \\
PROM & 13 & 4.33 \\
Fœto-maternal incompatibility & 02 & 0.67 \\
Nursery & & \\
Anemia & 14 & 4.67 \\
Malaria & 27 & 9.00 \\
Diabetes & 3 & 1.00 \\
heart Disease & 12 & 4.00 \\
sickle cell & 2 & 0.67 \\
Asthma & 4 & 1.33 \\
HBP & 31 & 10.33 \\
Hepatitis B & 02 & 0.67 \\
Trauma & 02 & 0.67 \\
Unknown cause & 121 & 40.33 \\
\hline
\end{tabular}

HBP $=$ High Blood Pressure. $\mathrm{RPH}=$ Retroplacental Hematoma. PROM = Prelabor Rupture of Membranes.

\subsection{The Main Complications Encountered}

Acute psychosis was found in $4.67 \%, 3.33 \%$ of the pregnant women had hemorrhaging at the delivery and endometritis was found in $2.67 \% .89 .33 \%$ had no complications.

\section{Discussion}

\subsection{Epidemiological Aspects of Fetal Death}

\subsubsection{Prevalence}

The prevalence of $3.64 \%$ found in this study is identical to that found (3.9\%) by TajiLeki S. et al. in 2018 in Bunia in the DRC [7], but lower than those of several African authors: Kyembwa Mulyumba Michel in Goma (4.5\%) and Ignace Bwana Kangulu (13.9\%) in Kamina in DRC, Andriamandimbison Z. (5.22\%) in Madagascar, Diallo MH (6.95\%) in Guinea [3] [4] [8] [9].

The lower rates are those of Moutongo [10] in Mali, 2.62\% at National Hospital "G” and Z.N. Andriamandimbison 0.44\% in Creil in France [11].

The prevalence found in this hospital can be explained by the fact that the study was made in the national reference center but also by the inadequacies in the health policy itself of our country. Indeed, the rates varying between developed and developing countries show all the effort that remains to be done in the 
prevention of fetal deaths in uterus in our countries.

\subsubsection{Maternity Age}

The most represented age group was $20-35$ years old with $77.67 \%$ in our study (Table 1); Like Kyembwa Mulyumba Michel [3] who found that the age group of (20 - 34 years) was $72.7 \%$ and TajiLeki S [7], 62.07\% in Bunia in the DRC. In Mali Traore M. [5], who found 59\% of fetal death in uterus cases in patients aged 20 to 34 years. Diallo in Guinea, found that pregnant women over 30 years of age were more represented [9].

This could be explained by the fact that this age group is in the period of obstetrical activity by excellence and not because it constitutes the maternity age group at risk. The age of over 35 years is more represented because the risk of chromosome abnormality and associated morbid pathology is more frequent.

\subsubsection{Mode of Admission}

The referred and evacuated patients constituted respectively $51 \%$ and $28 \%$ of the pregnant and 21\% had come by themselves. In Traore's study [5], in Mali, 12.7\% were referred and $27.8 \%$ evacuated, with $59.5 \%$ of patients coming on their own.

In fact the maternity office of Sylvanus Olympio Hospital is the national health reference center. All patients came from all peripheric centers.

\subsection{Obstetric History}

\subsubsection{Fetal Deaths History}

Studies on the management of fetal death in utero have placed special emphasis on the risk of women with an obstetrical history of fetal death [12]. Our study shows that $74.33 \%$ of pregnant women had no history of fetal death in utero compared to $5.67 \%$ of pregnant women with at least one history of fetal death in utero. In Traore's study [5], 93.7\% had no history and 6.3\% had an antecedent fetal death in uterus.

After analyzing these different results, it can be said that an antecedent of fetal death in uterus can constitute in itself a favorable factor. These results account for the conjunction of several variables including maternity age, the absence of prenatal consultation and the precarious socio-economic situation experienced by Togolese pregnant women like Kubuya [12], found in his study in Walikale (DRC).

\subsubsection{Gravidity-Parity}

In our study, multigravida women have a higher risk of fetal death in uterus, which is $49 \%$ of pregnant women. This rate is higher than that of Traore M.M [5], who found in Mali in 2014, 33\% of multigravida women. Kubuya [12], in the DRC found that $57.4 \%$ was multigravida and multiparous.

This high rate of multigravida women could be explained by risk factors related to pregnancies too close together; the precarious socio-economic situations of these pregnant women with no or derisory income.

The nulliparous and women with less than two children were more concerned 
in the study of Amrouche Souhila [2] in Algeria and TajiLeki S in Bunia (DRC) [7].

The $41 \%$ fetal death in uterus rate among nulliparous in this study could be explained by maternity age and inexperience at pregnancy on the part of these pregnant women.

\subsubsection{Gestational Age}

Fetal death in uterus occurred in pregnant women in $39 \%$ of cases between [ 28 37 Weeks]. In Guinea, Diallo [9] found $60 \%$ of fetal death in uterus occurred between 27 - 31 weeks.

Indeed, the gestational age factor does not explain the fetal death in utero. It is in fact at this period of pregnancy that the pathologies contributing to the fetal death In Uterooccur (hypertensive disorders of pregnancy pathologies and Prelabor Rupture of Membranes).

\subsubsection{Prenatal Consultation}

In our study, the rate of fetal death In Utero in pregnant women with no prenatal consultation was $17 \%$. Traore M. [5] had almost found the same rate of $16.4 \%$ in Mali in 2014. In Algeria this rate was only 6\% [2].

In contrast, in Congo Kyembwa found that the fetal death in uterus was higher among those who had less prenatal consultation [3]

Despite the high number of prenatal consultation, the fetal death rate in uterus still remains high. This paradoxical observation raises questions and we believe that the quality of services, the lack of qualified providers have an important role to play in these fetal deaths. In addition, the pathology related to pregnancy is a contributory factor to the deaths.

\subsection{Etiological Factors during Pregnancy}

\subsubsection{Pre-Eclampsia and Its Complications}

Pre-eclampsia by itself accounts for $24 \%$ of the etiologies of fetal death in uterus in our study. TajiLeki S in Bunia (DRC) [7] found the same 24.1\%. This rate is higher than the one in Moutongo's studies [10] who found that in Mali among $8.89 \%$ of predictable causes, $13 \%$ derive from pre-eclampsia and $13.3 \%$ of fetal deaths from eclampsia. In France 15.4\% is due to eclampsia, 19\% due to retroplacental hematoma [11].

Pre-eclampsia remains a common cause of fetal death in uterus in our countries where the quality of pregnancy monitoring is often problematic. Eclampsia and retroplacental hematoma are serious conditions, most often complicating pre-eclampsia with a very high risk of fetal death in uterus. RPH is the most common placental cause. This high level of RPH could be explained mainly by the pathophysiology of the condition; failure of pregnancy monitoring; the ineffective management of pre-eclampsia prior to RPH and the late reference of pregnant women to the standard care. We believe that careful antenatal surveillance could actually result in a significant decline in fetal mortality during this pathology. 


\subsubsection{Placenta Previa}

It presents $0.33 \%$ of fetal deaths in uterus in our study. Diallo [9] found that placentaprevia is a factor of hemorrhagic. He is very serious because of acute anemia, prematurity and delay in the procedure. This rate is lower than those of Moutongo [10] who found in Mali in 2000, 5.56\% among predictable causes.

\subsubsection{Pre-Labor Rupture of Membranes (PROM)}

During our study it was associated with fetal death in $4.33 \%$. Our rate is lower than the one of Traore M. [5] who found 13.92\% and Amrouche Souhila in Algeria where the PROM was 6\% [2] and 5.7\% for TajiLeki Sin DRC [7].

When the egg opens before the labor begins, the fetus is threatened with death if the delivery is not done in a short period time because of the oligoamnios, funicular compression, and the infection it causes (chorioamniotitis).

\subsubsection{Malaria}

Fetal death in uterus occurred in $9 \%$ of pregnant women with malaria. This rate is higher than the one of Moutongo [10] who found in Mali in 2000, 2.5\%. We believe that these high rates are due, on one hand to the geographical situation (zone with high parasitic endemia), to the irregularity or the absence of Prenatal consultation in our pregnant women and on the other hand to a decrease of the immunity during pregnancy, where the pathologies are most often noisy, breakage of the antimalarial prophylaxis (sulfadoxine-pyrimethamine) in our health structures and the difficulties of using a long-lasting insecticidal nets action by some pregnant women.

\subsubsection{Anemia}

From the 300 fetal death cases, we recorded $4.67 \%$ severe anemia. This rate is higher than Moutongo's rate [10] who found in Mali in 2000, 3.89\%. These cases of anemia almost always occur on precarious socio-economic grounds. The high rate of anemia in our series is thought to be due to a lack of systematic iron supplementation during prenatal consultation and to the disruption of the free distribution of Folic Acid Iron in health centers, but also to malaria, malnutrition and digestive parasitosis which pregnant women suffer from.

\subsubsection{Unknown Etiologies}

It represented 40.33\%; this rate is higher than that of Amrouche in Algeria 31\% [2]. This high rate in our hospital could be explained by the difficulties in carrying out etiological assessments to our pregnant and the refusal or not practical autopsy in our structure. These difficulties are of an economic nature; cultural and religious practices. All this makes the etiologies more unknown in our practices in Togo.

\subsection{Prognosis}

The vaginal delivery was the expulsion way except in $3.3 \%$. Traore $\mathrm{M}$ found $86.07 \%$ of vaginal delivery and $13.93 \%$ of Caesarean section [5]. In Algeria, 
Amrouche found $6 \%$ caesarean section and $94 \%$ natural delivery [2]. Indeed, when the fetus is dead, the natural ways are preferred except in the irreducible cases where cesarean section is indicated for maternal rescue.

\subsubsection{Psychological Complications}

Acute psychosis was more recorded at $4.67 \%$ in our study. This could be explained by the lack of support for pregnant women and their families as soon as the diagnosis of the fetal death in uterus is confirmed. This is the result of a total absence of psychologist in the maternity ward or qualified staff for this purpose in the service. In addition, the lack of infrastructure is an important factor to mention. For instance, mothers who have been admitted with a fetal death In Uterostay in the room with those whose babies are alive.

\subsubsection{Hemorrhage of Deliverance}

It represented 3.33\% in our study. Diallo had found 3 cases and Amrouche 6\% in Algeria. This rate could be explained by the late reference, a late artificial activation of expulsion of the dead fetus, the difficulty to perform the hematological assessment in case of fetal death. In uterus, the poor supervision of our pregnant women is due to the small number of healthcare personnel and their working conditions.

\subsubsection{Infectious Complications}

We recorded $1.67 \%$ endometritis in our study. This can be explained on the one hand by the prelabour rupture of membranes and obstetric treatment and, on the other hand by the poor follow up with mothers and the shortage of the staffs.

\subsection{Limits}

This study does not really prove the link between the etiologies or factors identified and fetal death. There is a possibility of selection bias; and therefore the observed prevalence may be, over or underestimated. Furthermore, we do not include intrapartum fetal deaths or deaths at birth. Case witnesses study can prove the link and give answers to certain questions about fetal death in uterus.

\section{Conclusions}

In uterus fetal death remains common in our country. The main causes were pre-eclampsia, RPH, malaria, anemia and PROM. The unknown causes are in fact undesirable causes for structural, cultural, and economic reasons. The etiological investigation is posteriori, especially if the autopsy and the examination of the placenta are not carried out.

Quality prenatal consultation and timely referral of high-risk pregnancies will effectively address preventable causes.

\section{Conflicts of Interest}

The authors declare no conflicts of interest regarding the publication of this paper. 


\section{References}

[1] Quibel, T., Bultez, T., Nizard, J., Subtil, D., Huchon, P. (2014) RozenbergMortsfœtales in Utero. Journal de Gynécologie Obstétrique et Biologie de la Reproduction, 43, 883-907.

[2] Amrouche Souhila A.R.N. (2017) La mort fœtale in utero. Thèse, présentée et soutenue publiquement le 30 Mai.

[3] Michel, K.M., Grace, K.E., Sosthène, T.L., Mathumo, M., Jeremy, L.O. and Bosunga, K. (2018) Mort in utéro: Fréquence et facteurs de risque dans la ville de Goma en République Démocratique du Congo. International Journal of Innovation and Applied Studies, 23, 661-666. http://www.ijias.issr-journals.org/

[4] Andriamandimbison, Z., Randriambololona, D.M.A., Rasoanandrianina, B.S. and Hery, R.A. (2013) Étiologies de la mort fotale in utero: À propos de 225 cas à l'hôpital de Befelatanana Madagascar. Médecine et Santé Tropicales, 23, 78-82

[5] Modibo, T.M. (2014) Etude de la mort fotale in utéro à la maternité du CS Réf du district de Bamako. Thèse Med, Bamako, p. 91.

[6] Baeta, S., akpadza, K., Hodonoua, K.S. and Idder-Abdoulaye, J. (1991) Etiologies des morts fotales in utero; à propos de 308 cas observés de janvier 1984à Juin 1985. Pub Med Afr, 118, 14-22.

[7] Taji Leki, S., Osundja, L., Kyembwa Mulyumba, M., Sangani, M., Habiragi, M., Matumo, M., Komanda Likweke, E. and Bosunga, K. (2018) Epidemio-Clinical Profile of Death in Utero in Bunia in the Democratic Republic of Congo. International Journal of Recent Scientific Research, 9, 7789-27792. https://doi.org/10.24327/IJRSR

[8] Kangulu, I.B., Albert, A.M.T.A., Lumbule, J.N. and Muenze, P.K. (2016) Fréquence et facteurs de risque maternels de la mort fœtale in utero à Kamina, République Démocratique du Congo. The Pan African Medical Journal, 23, 144.

https://doi.org/10.11604/pamj.2016.23.114.7817

[9] Diallo, M.H., BalDé, I.S., Diallo, O., Diallo, B.S., BalDé, A., Barry, H., BalDé, M.D. and Keita, N. (2016) Mort fœtale in utero (MFIU): Aspect sociodémographique, prise en charge et pronostic Maternel à la Maternité de l'hôpital régional de MAMOU. Revintscméd-RISM-2016.

[10] Moutongo Frieda Agnès EYIDI (2000) La mort fotale in utero dans le service de gynéco-obstétrique de l'hôpital national du Point G de 1992-1999. Thèse de Médecine, Bamako, 95 p.

[11] Andriamandimbison, Z.N., Ahounkeng, N.P., Adjoby, R.C., Ramarokoto, M.F., Dipace, C. and DiengaTshofu, E. (2014) Mort fotale in utero: Étiologies et prise en charge à l'hôpital Laennec de Creil. Méd. Périnat., 6, 49-56.

[12] Georges, K.K. (2017) Aspect épidémiologique, clinique et thérapeutique de la mort fœetale in utero au sein de l'hôpital général de référence de walikale. Annales de P UNIGOM, 7. 